\title{
Effect of single and multi-site calibration techniques on hydrological model performance, parameter estimation and predictive uncertainty: a case study in the Logone catchment, Lake Chad basin
}

\author{
E. Nkiaka ${ }^{1} \cdot$ N. R. Nawaz ${ }^{1} \cdot$ J. C. Lovett ${ }^{1}$
}

Published online: 20 October 2017

(c) The Author(s) 2017. This article is an open access publication

\begin{abstract}
Understanding hydrological processes at catchment scale through the use of hydrological model parameters is essential for enhancing water resource management. Given the difficulty of using lump parameters to calibrate distributed catchment hydrological models in spatially heterogeneous catchments, a multiple calibration technique was adopted to enhance model calibration in this study. Different calibration techniques were used to calibrate the Soil and Water Assessment Tool (SWAT) model at different locations along the Logone river channel. These were: single-site calibration (SSC); sequential calibration (SC); and simultaneous multi-site calibration (SMSC). Results indicate that it is possible to reveal differences in hydrological behavior between the upstream and downstream parts of the catchment using different parameter values. Using all calibration techniques, model performance indicators were mostly above the minimum threshold of 0.60 and 0.65 for Nash Sutcliff Efficiency $(N S E)$ and coefficient of determination $\left(R^{2}\right)$ respectively, at both daily and monthly time-steps. Model uncertainty analysis showed that more than $60 \%$ of observed streamflow values were bracketed within the $95 \%$ prediction uncertainty (95PPU) band after calibration and validation. Furthermore, results indicated that the SC technique outperformed the other two methods (SSC and SMSC). It was also observed that although the SMSC technique uses streamflow data from all gauging stations during calibration and validation, thereby taking into account the catchment spatial variability, the choice of each calibration
\end{abstract}

\footnotetext{
E. Nkiaka

gyenan@leeds.ac.uk

1 School of Geography, University of Leeds, Leeds, UK
}

method will depend on the application and spatial scale of implementation of the modelling results in the catchment.

Keywords Multi-site calibration - SWAT · Uncertainty · Parameters estimation - Predictive uncertainty - Logone catchment · Lake Chad basin

\section{Introduction}

The rate of hydrological change in the Lake Chad Basin (LCB) has increased in recent decades. Lake Chad is an endorheic lake located in the Sudano-Sahel transition zone of the Central Africa region. Between 1960 and 2000 the lake experienced one of the most significant and sustained reductions in rainfall recorded anywhere in the world, which caused the lake area to shrink by more than $80 \%$ (Odada et al. 2005). However, the shrinkage in lake size cannot be attributed wholly to a reduction in rainfall. Construction of numerous dams on the feeder rivers of the lake for irrigation projects have reduced inflows into the lake by about $50 \%$ (Odada et al. 2005).

More recently, drought has given way to floods due a recovery in rainfall (Nkiaka et al. 2016a). However, water availability for agriculture, pastoral activities, wetland ecology and contribution as inflow into the lake continues to be variable due to the erratic nature of this rainfall. Under future projected climate change Sahelian semi-arid ecosystems such as the LCB are expected to witness increased frequency of droughts and floods (Yang et al. 2016). This will lead to social and economic problems as the rising population in the LCB is leading to tension among water users (Ngatcha 2009). A study by Okpara et al. (2015) reported that climate-induced water scarcity and droughts in the LCB could combine with factors such 
as population increase, poverty and political instability to create the necessary conditions for armed conflict. An improved understanding of the main hydrological processes and feedback mechanisms in the LCB will contribute to guiding future water management policy.

The LCB is a very heterogeneous basin with spatially variable land use, soil classes, topography and a strong rainfall gradient from north to south. To fully understand the hydrological characteristics of the basin, this spatial variability needs to be included in the modelling process. This can be achieved by using distributed catchment hydrological models (CHMs), which require careful calibration and validation. This process is a pre-requisite for model application because it reduces model uncertainty and increases user confidence in the model predictive capabilities.

Spatially distributed CHMs can be used for modelling different catchment processes, including evapotranspiration, surface runoff, interception, infiltration, percolation and groundwater flow. They can also be used to investigate the impacts of land use change, climate change and agricultural activities at a catchment scale (Wu and Chen 2013; Athira and Sudheer 2015; Zhou et al. 2015; Shi et al. 2016), making them a useful tool to help decision makers better understand environmental problems and design appropriate mitigation strategies. Given the current technological advancement in the acquisition and storage of hydro-meteorological data, the use of spatially distributed, physically based CHMs to enhance management decisions at basin scale is receiving increasing attention from the scientific community (Golmohammadi et al. 2014; Leta et al. 2017).

The high degree of spatial variability in catchment characteristics requires careful calibration of the model so as to obtain consistent results among all the gauging stations within the catchment. However, calibration of CHMs to determine a suitable set of parameter values that can describe the hydrology of the catchment is not always an easy task (Zhang et al. 2016). Studies have shown that the parameter set used to calibrate CHMs against flow measured only at the catchment outlet (single-site calibration (SSC)) may not produce similar results at other internal hydrometric stations within the catchment (Wang et al. 2012; Wi et al. 2015; Leta et al. 2017). Furthermore, several researchers have demonstrated the effectiveness of calibrating CHMs with data from different parts of the catchment using simultaneous multi-site calibration (SMSC) over SSC (Wang et al. 2012; Wi et al. 2015; Chaibou Begou et al. 2016).

SMSC techniques that use data from different sites within the catchment to constrain the model are expected to produce better results because spatial variability in the catchment is represented through different parameter values. Nevertheless, some researchers e.g. (Shrestha et al. 2016) have reported that no significant improvements were observed by applying the SMSC compared to SSC especially for flow simulation. Despite this, the application of SMSC and SSC techniques in hydrological modelling is well established, and many studies have demonstrated the superiority of the former technique to the latter (Wang et al. 2012; Chaibou Begou et al. 2016; Shrestha et al. 2016).

While hydrological modelling has been conducted across most major African basins (Cohen Liechti et al. 2014; Ollivier et al. 2014; Aich et al. 2015; Chaibou Begou et al. 2016), there are few studies on hydrological modelling in the LCB and its associated sub-basins. $\mathrm{Li}$ et al. (2005) investigated hydrological variability in the LCB using the land surface model Integrated Biosphere Simulator (IBIS), and the Hydrological Routing Algorithm (HYDRA). They concluded that the hydrology of the LCB was very variable in space and time. Candela et al. (2014) also carried out a groundwater modelling study in the LCB using MODFLOW and concluded that groundwater plays a non-negligible role in the hydrology of the basin.

Results from the studies by Li et al. (2005) and Candela et al. (2014) are highly generalized for the LCB and could be misinterpreted at sub-basin scale given the size of the LCB (approximate area $2.5 \times 10^{6} \mathrm{~km}^{2}$ ) and the fact it covers a range of ecological zones (hyper arid, arid, semiarid and Sudano). Such generalizations may not be useful for effective and robust planning and management of water resources. Thus, it is necessary to reduce the spatial scale of similar studies in the basin to gain an insight into the dominant hydrological processes at sub-basin scale. Of the numerous sub-basins that make up the LCB, the Logone catchment was selected for this analysis. The reasons for selecting the Logone catchment include: (1) it covers two ecological zones (Sudano and semi-arid), (2) it contributes significantly to Lake Chad inflows, (3) it is a transboundary catchment shared by three countries (Cameroon, Chad and Central Africa Republic).

The aim of this study was to develop a hydrological model of the Logone catchment using the Soil and Water Assessment Tool (SWAT) model. This was achieved through the following specific objectives: (1) to compile datasets to implement the SWAT model on the Logone catchment; (2) to calibrate and validate the model at daily and monthly time-steps at three gauging stations including the outlet of the catchment; (3) examine the benefits of multiple calibration techniques (SSC, SMSC and sequential calibration (SC)) for hydrological analysis; and (4) select from the different calibration techniques the model that best describes the hydrological processes of catchment and use that model to attempt a description of the catchment hydrology. 


\section{Materials and methods}

\subsection{Model description}

The SWAT model is a semi-distributed, continuous timestep simulation model that can run at a daily, monthly or yearly time-steps (Gassman et al. 2007; Arnold et al. 2012). It is capable of simulating hydrological processes, impacts of climate and land use changes, water use management, water quality and quantity assessments (Gassman et al. 2007; Wu and Chen 2013; Athira and Sudheer 2015). The model was used in this study because it has been successfully applied in other catchments in Africa e.g. (Cohen Liechti et al. 2014; Akpoti et al. 2016; Chaibou Begou et al. 2016). However, previous application of SWAT in the LCB has not been reported in the literature.

In this study, we focus only on water quantity simulation accomplished through two steps: (1) the land phase of the hydrological cycle, which controls the amount of water transferred to the main channel from each sub-catchment, and (2) the routing phase, which involves the movement of water through the channel network to the outlet. The hydrologic cycle in the land phase of the model is simulated using the water balance equation as:

$S W_{t}=S W_{0}+\sum_{i=1}^{n}\left(R_{\text {day }}-Q_{\text {surf }}-E_{a}-W_{\text {seep }}-Q_{g w}\right)$

$S W_{t}$ is the final soil water content $(\mathrm{mm}), S W_{O}$ is the initial water content $(\mathrm{mm}), R_{\text {day }}$ is the amount of precipitation on day $i(\mathrm{~mm}) Q_{\text {surf }}$ is the amount of surface water runoff on day $i(\mathrm{~mm}), E_{a}$ is the amount of actual transpiration on day $i(\mathrm{~mm}), W_{\text {seep }}$ is the amount of water entering the vadose zone from the soil profile on day $i(\mathrm{~mm})$ and $Q_{g w}$ is the amount of return flow on day $i(\mathrm{~mm})$. Details of equations and methods used to estimate various hydrological components can be found in Neitsch et al. (2011).

During model development, SWAT divides a catchment into sub catchments using digital elevation model data. The spatial distribution of hydrological processes over each sub-catchment is represented through hydrologic response units (HRUs), which are used to further divide the subcatchments into smaller units based on a homogeneous combination of land use class, soil type, slope class and management within each sub-catchment.

Three options are available for estimating potential evapotranspiration (PET) in the SWAT model: Hargreaves, Priestley-Taylor and Penman-Monteith. The Hargreaves method was applied owing to the less onerous data demands (minimum and maximum temperature). This method has been used in other modelling studies in the region using SWAT model with reasonable results obtained (Chaibou Begou et al. 2016). Furthermore, Droogers and
Allen (2002) compared Penman-Monteith and Hargreaves reference evaporation estimates on a global scale and found reasonable agreement between the two methods $\left(R^{2}=0.895\right.$, RMSD $\left.=0.81\right)$. These authors suggested that, the Hargreaves method could be used in regions where reliable weather data was not available. Surface runoff was calculated using the Soil Conservation Service's curve number (CN2) method while flow routing was accomplished through the variable storage method (Neitsch et al. 2011). Model parameters that affect streamflow generation and propagation are summarized in Table 1 . The equations used for modelling wetlands are also available in relevant SWAT documentation (Neitsch et al. 2011).

\subsection{Study area}

The Logone catchment lies between latitude $6^{\circ}-12^{\circ} \mathrm{N}$ and longitude $13^{\circ}-17^{\circ} \mathrm{E}$. This is about $8 \%$ of the active basin area that covers about more than a million square kilometres (Adenle 2001) (Fig. 1a). It is a transboundary catchment located in the Sudano-Sahel transitional zone within the Lake Chad basin with an estimated catchment area of $86,240 \mathrm{~km}^{2}$ at the Logone Gana outlet (Fig. 1b). The catchment area is shared by Cameroon, Chad and Central Africa Republic. The Logone River has its source in Cameroon through the Mbere and Vina rivers, which flow from the north-eastern slopes of the Adamawa Plateau in Cameroon. It is joined in Lai by the Pende River from the Central Africa Republic and flows from south to north to join the Chari River in Ndjamena (Chad) after, which it continues flowing in a northward direction and finally empties into Lake Chad. The river has an estimated length of $1000 \mathrm{~km}$.

The climate in the catchment is characterized by high spatial variability and is dominated by seasonal changes in the tropical continental air mass (the Harmattan) and the marine equatorial air mass (monsoon) (Candela et al. 2014). There is a strong north-south rainfall gradient with a single rainy season occurring between April and October. Estimated average rainfall varies between $900 \mathrm{~mm} /$ year in the north to $1400 \mathrm{~mm} / \mathrm{year}$ in the south Nkiaka et al. (2016a) while mean annual temperature is $28^{\circ} \mathrm{C}$. Apart from some local mountains in the south and north-west, the catchment is very flat with an average slope of less than $1.3 \%$ in a south-north gradient.

\subsection{Data sources}

\subsubsection{Meteorological data}

Due to data scarcity in the LCB, global meteorological forcing data WATCH Forcing Data methodology applied to ERA Interim (WFDEI) (Weedon et al. 2014) was used to 


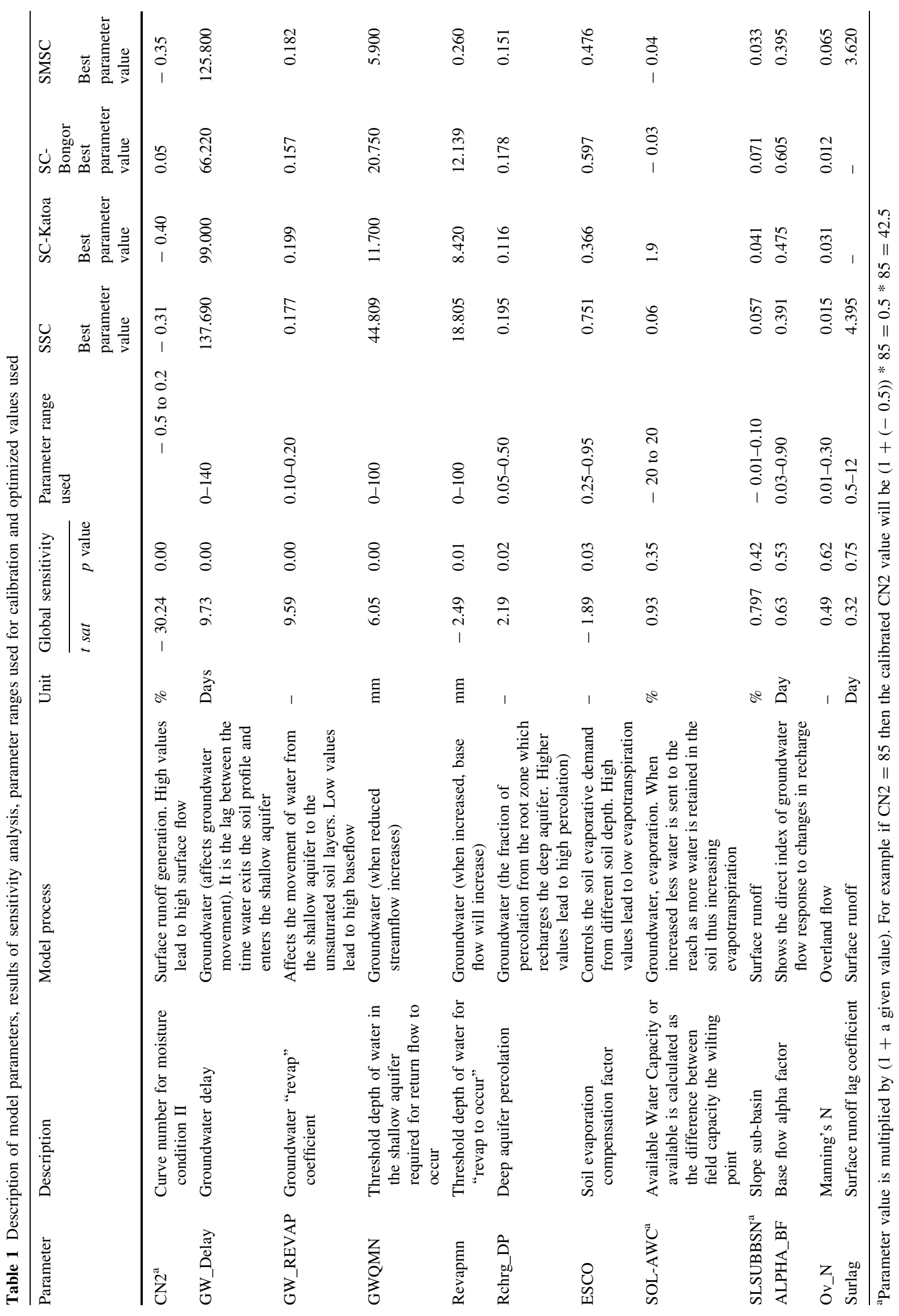


Fig. 1 Map of the study: Lake Chad basin showing the Logone catchment (a); and detailed map of the Logone catchment

(b) digital elevation model (DEM) in metres
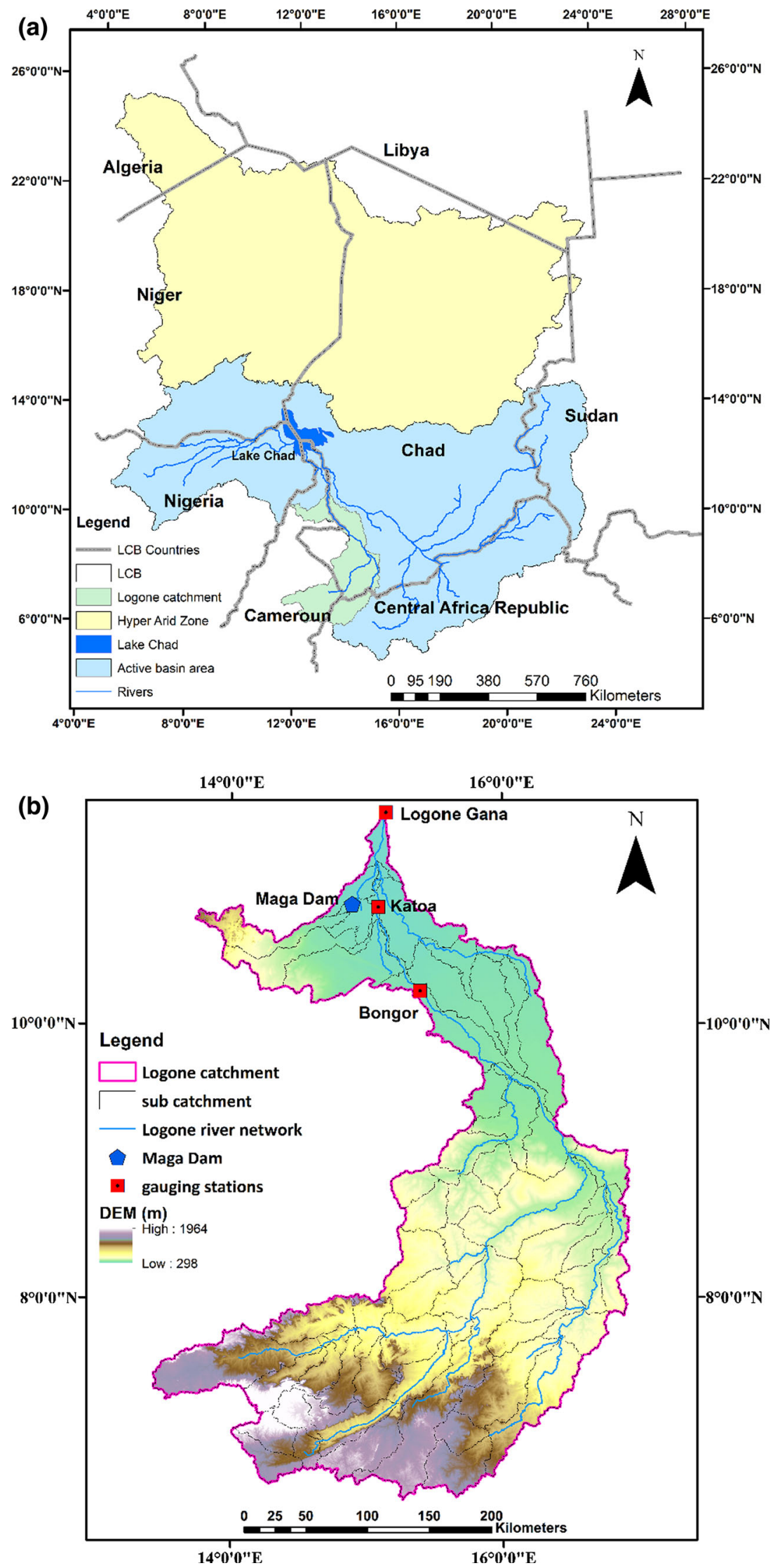
drive the model. WFDEI is a bias corrected dataset produced from Watch Forcing Data and ERA-Interim reanalysis via sequential interpolation to a $0.5^{\circ}$ resolution, elevation correction and monthly-scale adjustments based on CRU TS3.1/TS3.21 and GPCCv5/v6 monthly precipitation observations for 1979-2012 (Weedon et al. 2014). These are combined with new corrections for varying atmospheric aerosol-loadings and separate precipitation gauge corrections for rainfall and snowfall under the Water and Global Change (WATCH) programme. Only daily precipitation, minimum and maximum temperature values were used in this study.

The use of WFDEI for hydrological modelling is widely reported. For example Monteiro et al. (2015) used WFDEI and Climate Forecasting System Reanalysis (CFSR) as input to drive the SWAT model in the Tocantins catchment in Brazil and reported that WFDEI outperformed CFSR in simulating streamflow. Andersson et al. (2015) used WFDEI as input to drive Hydrological Prediction of the Environment (HYPE) across different basins in Europe and Africa and concluded that, this dataset improved streamflow simulation compared to Watch Forcing Data (WFD) based on ERA-40. In a previous study Nkiaka et al. (2017), compared the performance of CFSR, ERA-Interim and WFDEI for hydrological modelling in the Logone catchment and concluded that, WFDEI outperformed the other two datasets in simulating streamflow.

For the Logone catchment, the data was obtained for an area bounded by latitude $6^{\circ}-12^{\circ} \mathrm{N}$ and longitude $13^{\circ}-$ $17.25^{\circ} \mathrm{E}$ from https://dataguru.lu.se/ at a spatial resolution of $0.5^{\circ} .96$ grid points were selected within this rectangular area. Elevation data for WFDEI was obtained from the International Institute of Applied System Analysis (IIASA) available at ftp://ftp.iiasa.ac.at/WFD-land-long-lat-z.dat.

\subsubsection{River discharge data}

River discharge data was obtained from the Lake Chad Basin Commission (LCBC) at both daily and monthly time-steps covering the period 1997-2010. Gaps in the discharge data were infilled using Artificial Neural Networks Self-Organizing Maps (ANN-SOM) (Nkiaka et al. 2016b).

\subsubsection{Spatial data}

Digital Elevation Model (DEM) data used to delineate the catchment was obtained from the Shuttle Radar Topographic Mission (SRTM) at a spatial resolution of $90 \mathrm{~m}$ downloaded from http://www.cgiar-csi.org/. The quality of DEMs have been shown to vary from one source to another, which could have an impact on model parameters thereby compromising the quality of model results $(\mathrm{Wu}$ et al. 2008; Lin et al. 2013). However, Lin et al. (2013) investigated the impact of DEM spatial resolution on SWAT model results and reported that, the latter had a significant impact on water quality and sediment load simulation but simulated streamflow was not sensitive to DEM spatial resolution. Given that the purpose of this study was streamflow simulation, a DEM with spatial resolution of $90 \mathrm{~m}$ was used. Land cover/use maps were obtained from Climate Change Initiative Land Cover (CCILC) at a spatial resolution of $300 \mathrm{~m}$, obtained from www.esa-landcover-cci.org/. Soil data was obtained from the Food and Agricultural Organisation (FAO), Harmonize World Soil Database (HWSD) at a spatial resolution of $1 \mathrm{~km}$. The land use and soil maps of the study area are shown in Fig. 2. Soils are grouped according textural classes.

\subsubsection{Model setup}

To maximize the number of meteorological grid points used for simulating the model, a minimum drainage area of $750 \mathrm{~km}^{2}$ was used to delineate the catchment into $66 \mathrm{sub}-$ basins (Fig. 3) and 34 meteorological grid points were selected. The land cover was reclassified in ArcSWAT according to model input requirements with forest and agriculture dominating the land cover (Fig. 2 and Table 2). The land use map indicated 59 wetland areas in the catchment spread over 59 sub-basins occupying a total surface area of $1800 \mathrm{~km}^{2}$, making up about $2 \%$ of the study area. ArcGIS tools were used to create an artificial reservoir (the Maga dam) draining two rivers (Mayo Tsanaga and Mayo Boulo) and an outlet downstream of the reservoir. Multiple HRUs and area criteria were used for HRUs creation to take into account all land use classes especially wetlands. Threshold values for HRUs creation were fixed at 5 ha for land use given that the smallest wetland occupied an area of 5 ha while 2500 ha was used for slope and soil classes thereby, creating 406 HRUs.

Minimum and maximum water levels in the wetlands were assumed to vary within the range $0.50-1.0 \mathrm{~m}$ (Jung et al. 2011). This information was used to calculate the storage capacity of each wetland. The normal storage volume of the wetland was calculated as the product of the wetland area by minimum water level $\left(V_{\min }=0.5^{*} S A\right)$ while the maximum storage was taken as the product of wetland area by maximum water level $\left(V_{\max }=1.0^{*} S A\right)$. The fraction of each sub-basin draining into the wetland $f r_{i m p}$ was estimated as the ratio of the wetland area to the area of the corresponding sub-basin. As suggested by Wang et al. (2010), three wetland parameters $\left(f r_{i m p}, V_{\max }\right.$ and $V_{\text {min }}$ ) were calibrated. According to Wang et al. (2010), when $f r_{i m p}$ takes a lower limit or is very small, the wetland may not receive any inflow from the remaining portion of 


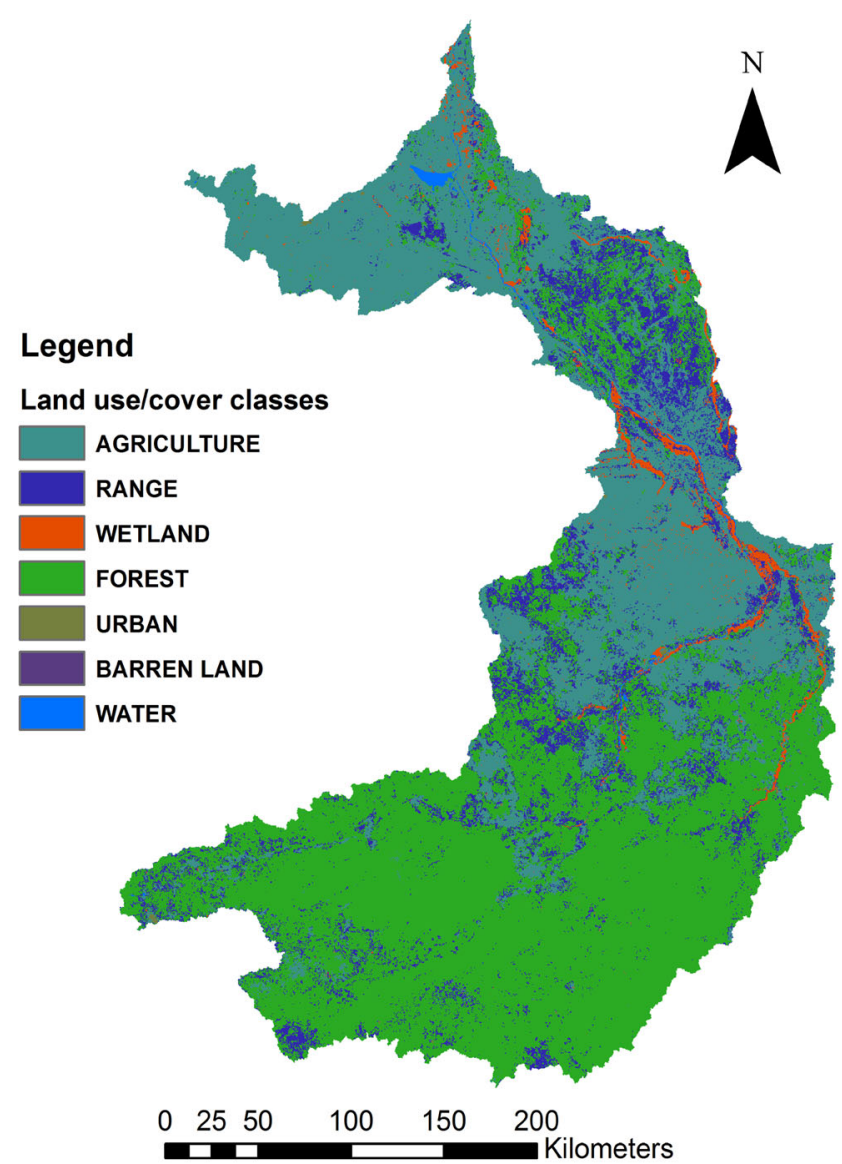

Fig. 2 Land use/cover and soil classes in the Logone catchment

the sub-basin. On the other hand, when $f r_{i m p}$ takes the upper limit, the wetland is considered to intercept all runoff generated in the sub-basin.

\subsection{Model sensitivity analysis, calibration, validation and uncertainty analysis}

Sensitivity analysis, calibration, validation and uncertainty analysis were implemented by the automated SWAT Calibration and Uncertainty Program software (SWAT-CUP) using the commonly applied Sequential Uncertainty Fitting algorithm (SUFI-2) (Abbaspour 2008). A global sensitivity analysis approach was used whereby all parameters are allowed to change at the same time. Sensitivity analysis was carried out for all the 26 flow related parameters using their ranges defined in relevant SWAT documents although only the most sensitive are reported in (Table 1). In Table 1, the larger the $t$-stat value in absolute terms, the more sensitive is the parameter. On the other hand, the $p$ values are used to determine the significance of the sensitivity results with values closer to zero considered to be more statistically significant.

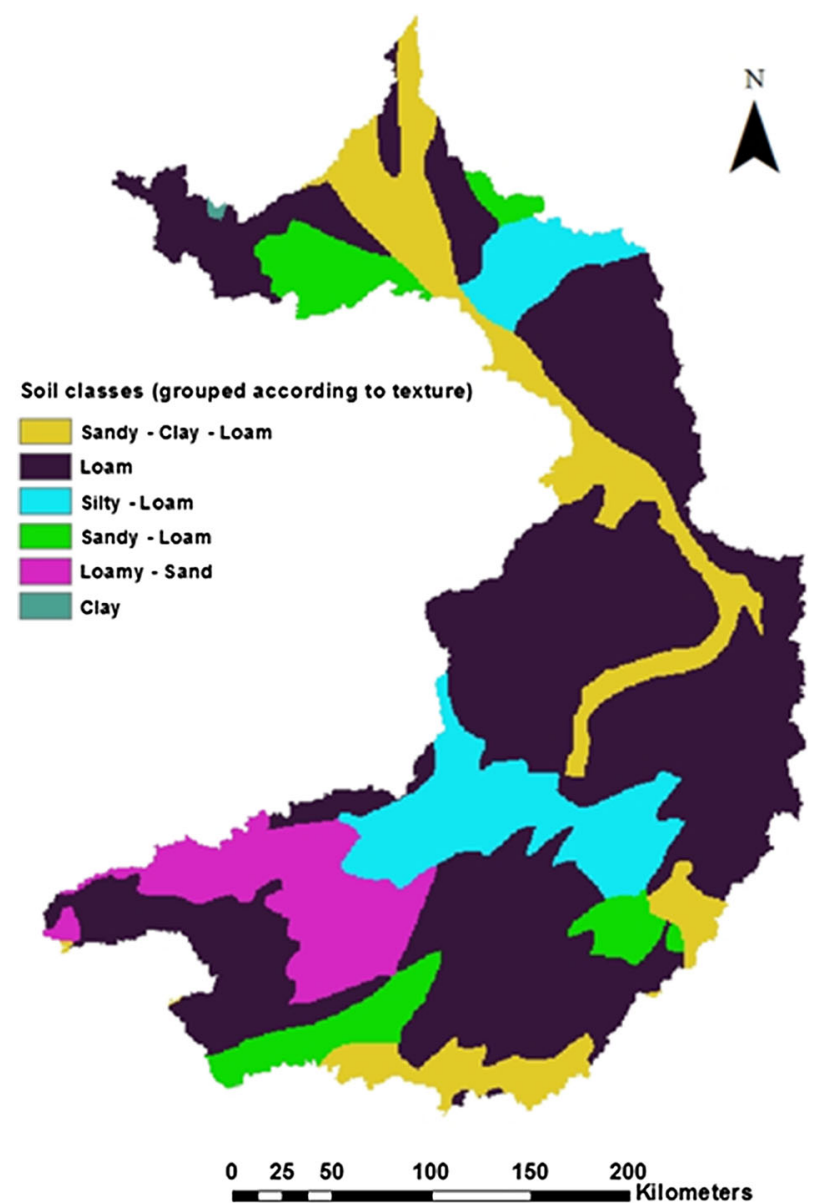

In this study, the following calibration techniques were applied: single-site calibration (SSC), sequential calibration (SC) and simultaneous multi-site calibration (SMSC). The SSC consist of changing and optimizing model parameters using flow data measured at the catchment outlet only. The SC technique is an approach whereby, the model is calibrated using flow data from different parts of the catchment beginning with the most upstream station and subsequently moving to downstream stations. Given that sub-catchments that contribute to flow may have different characteristics (soils, land use, topography), in the $\mathrm{SC}$ technique, only the parameters of the sub-basins located upstream of that hydrometric station are calibrated. Since all the hydrometric stations in the studied catchment are hydrologically connected, the model was first calibrated for the most upstream station Bongor (sub-basins 16-66) and subsequently Katao (sub-basins 5 and 12 and 16-66) (Fig. 3). SC was not carried out at Logone Gana because this station had already been calibrated using the SSC technique. Migliaccio and Chaubey (2007) recommend the use of SC technique for calibrating nested sub-basins with hydrologic connections. 


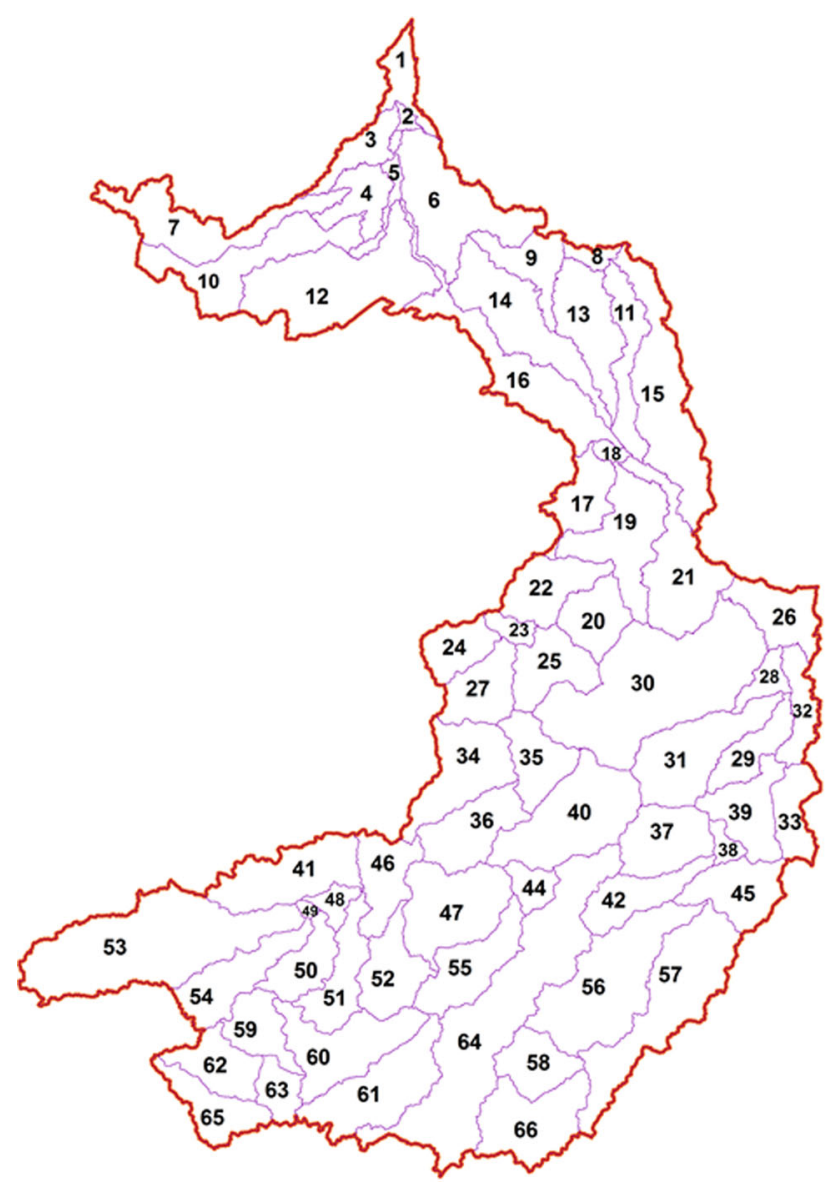

Fig. 3 Logone sub-basin numbers

Table 2 Land use/cover distribution in the catchment

\begin{tabular}{lll}
\hline Land use/cover class & Area $\left(\mathrm{km}^{2}\right)$ & Area $(\%)$ \\
\hline Agriculture & $28,311.71$ & 32.83 \\
Range & 10,288 & 11.93 \\
Wetland & 1800.63 & 2.09 \\
Forest & 45,356 & 52.59 \\
Urban & 96.95 & 0.11 \\
Barren land & 1.98 & 0.00 \\
Water & 387.34 & 0.45 \\
Total & 86,242 & 100 \\
\hline
\end{tabular}

Contrary to the SC technique used by Wi et al. (2015), Shrestha et al. (2016) and Leta et al. (2017), whereby the calibrated and optimized parameter set obtained in the upstream gauge is fixed while calibrating the downstream counterpart, that approach was not adopted in this study because of the hydrological connection between upstream and downstream hydrometric stations. Note that the same number of parameters and their ranges were used to initiate each calibration. During SC, the parameter "Surlag" was not calibrated at Bongor and Katoa stations because it is a basin-scale parameter.

In contrast to SC and SSC techniques, the SMSC consisted of using flow data from all the hydrometric stations to calibrate the model by changing and optimizing parameters of all the sub basins at the same time. The aim of this approach is to look for suitable parameter values capable of producing satisfactory model results at all gauging stations at the same time. The advantage of this technique is a considerable reduction in computational time compared to the SC technique because all the gauging stations are calibrated at the same time. The SMSC technique has been applied by many researchers e.g. (Wi et al. 2015; Leta et al. 2017).

The model was simulated from 1997 to 2010 of which 1997-1999 was used as the warm-up period, 2000-2007 served as the calibration period for daily and monthly timesteps while 2008-2010 served as validation period for monthly time-step only. Due to the lack of sufficient daily observed streamflow data, the model was validated only at monthly time-step. In the calibration process, parameters such as soil water holding capacity (SWC) and surface runoff curve number at soil moisture condition II (CN2) that are spatially variable were adjusted using global multipliers or relative change to their original values. This approach is used to preserve the natural variability and heterogeneity of the catchment. The calibration process consisted of running 500 simulations in each iteration with the parameter set shown in Table 1. The ranges of the best parameter set obtained in the previous iteration was substituted and used in the next iteration until the results were judged to be acceptable.

Model validation consisted of running 500 iterations using the best parameter set obtained from the last calibration. The results of the SSC were also validated at upstream gauging stations (Katoa and Bongor) at daily and monthly time-steps by running the model during the same time period used for SSC with the behavioral parameter set obtained at the outlet. A similar approach has been used for validating the SSC technique by several researchers e.g. (Wang et al. 2012; Wi et al. 2015; Chaibou Begou et al. 2016). While SC results were validated at Bongor using independent monthly flow and rainfall data from 2008 to 2010, SMSC was validated at Logone Gana and Bongor using data from the same time period. Finally, the SMSC simulation number that produced the best output was used to calculate the water balance for the whole catchment during the calibration and validation periods.

Recently, Onyutha (2016) stated that the choice of a particular statistical "goodness-of-fit" measure greatly influences the judgement of the model performance. To eliminate subjectivity in assessment of the model performance, the well-known Nash-Sutcliffe Efficiency (NSE) 
was complemented by two other metrics (1) coefficient of determination $\left(R^{2}\right)$, and (2) Percent Bias (PBIAS). The NSE is used to assess the predictive capacity of the model and measures how well the observed and simulated flows match. The $R^{2}$ measures how well the observed data is correlated to the simulated data and varies from 0 to 1 . PBIAS indicates the average tendency of the simulated flows to be over/underestimated compared to observed flows. Although Moriasi et al. (2007) stated that NSE $>0.50, R^{2}>0.60$ and PBIAS $\pm 25 \%$ for calibrated models results at monthly time-step may be considered to be satisfactory, in this study, the threshold was set at $N S E>0.60, R^{2}>0.65$. The model evaluation metrics are calculated as:

$N S E=1-\left[\frac{\sum_{i=1}^{n}\left(x_{i}-y_{i}\right)^{2}}{\sum_{i=1}^{n}\left(x_{i}-\bar{x}^{2}\right.}\right]$

$R^{2}=\frac{\sum_{i=1}^{n}\left[\left(x_{i}-\bar{x}\right)\left(y_{i}-\bar{y}\right)\right]}{\sum_{i=1}^{n}\left[\left(x_{i}-\bar{x}\right)^{2}\right] \sum_{i=1}^{n}\left[\left(y_{i}-\bar{x}\right)^{2}\right]}$

$P B I A S=\left[\frac{\sum_{i=1}^{n}\left(X_{i}-Y_{i}\right)}{\sum_{i=1}^{n} X_{i}}\right] \times 100$

where $x_{i}=$ observed discharge; $y_{i}=$ simulated discharge; $\bar{x}=$ mean of observed discharge; $n=$ number of observations.

The degree of uncertainty in the calibrated/validated model was quantified using the $p$-factor and $r$-factor. The $p$-factor represents the percentage of observations bracketed by the $95 \%$ prediction uncertainty (95PPU) while the $r$-factor is the average width of the 95PPU band. The 95PPU is calculated at the 2.5 and $97.5 \%$ confidence interval of observed streamflow obtained through Latin hypercube sampling. In SUFI-2, the goal is to minimize the width of the uncertainty band and enclose as many observations as possible (Abbaspour 2008). The p-factor can vary between 0 and 1 with 1 representing the most preferred value which means, all the observations are captured by prediction uncertainty, while the desirable value for $r$ factor is $<1.5$. Therefore, a compromise has to be made between reducing $r$-factor closer to $<1.5$ and $p$-factor $>0.70$ (Abbaspour 2008).

\section{Results and discussion}

Sensitivity analysis was carried out using the SMSC technique because this approach uses streamflow data from all the hydrometric stations in the catchment. Results obtained indicated that, soil moisture condition curve number (CN2), which controls surface water runoff is the most sensitive parameter (Table 1). This was followed by parameters that control groundwater storage and flow. GW_revap, which controls the movement of water from the shallow aquifer to the unsaturated soil layers was also ranked among the most sensitive. The sensitivity analysis results suggest that groundwater plays an important role in the catchment hydrology.

\subsection{Model performance}

\subsubsection{Model performance for single site calibration}

The SSC technique was used to calibrate the model at the outlet (Logone Gana) and to validate it at Katao and Bongor located upstream. The model was also validated using independent data at monthly time-steps at the outlet. The NSE and $R^{2}$ values obtained during calibration and validation lie in the range $0.64 \leq N S E \leq 0.78$ and $0.65 \leq R^{2} \leq 0.88$, respectively. These results are above the threshold defined in this study (Table 3). Results for model calibration and validation at monthly time-steps using independent data are mixed with cases of peak flow over/underestimation observed in some years (Figs. 4a, 7a). It was also observed during SSC validation at upstream stations that the model overestimated peak flows in most years at Katoa and slightly underestimated it in some years at Bongor (Fig. 4b, c). The same results were obtained at monthly time-steps (Fig. 7b, c). Notwithstanding, results obtained at the outlet of the catchment are comparable to those obtained at the outlets of other Sudano-Sahel catchments e.g. by Chaibou Begou et al. (2016) at the outlet of Bani catchment using SWAT and by Aich et al. (2015) at the outlet of Niger basin using SWIM model.

From streamflow hydrographs, it can be observed that although the model had difficulties in simulating peak flows at some stations, low flows were adequately simulated at both time-steps (Figs. $4 \mathrm{a}-\mathrm{c}, 7 \mathrm{a}-\mathrm{c}$ ). It can also be observed from those hydrographs that despite the over/ underestimation of peak flows, the timing of peak flows was well reproduced at both time-steps with only a few cases of lag observed in some years especially at the outlet (Fig. 4a). Model prediction of water balance using the SSC technique at both time-steps can be considered to be satisfactory during calibration at the outlet and validation at the upstream stations given that PBIAS values obtained all lie within the limits defined in this study (Table 3).

Results obtained from the SSC technique indicate that the model performed better during validation at upstream gauging stations compared to calibration at the outlet during the same period. These results indicate that the parameters used to constrain the model at the outlet may not be representative of the whole catchment. The underperformance could be attributed to hydraulic modifications that exist downstream before the gauging station at Logne 
Table 3 Results of model calibration, validation and uncertainty analysis

\begin{tabular}{|c|c|c|c|c|c|c|c|c|}
\hline \multirow[t]{2}{*}{ Time step } & \multirow[t]{2}{*}{ Calibration method } & \multirow[t]{2}{*}{ Gauge location } & \multirow[t]{2}{*}{ Calibration/validation period } & \multicolumn{2}{|c|}{$\begin{array}{l}\text { Performance } \\
\text { index }\end{array}$} & \multirow[t]{2}{*}{ PBIAS (\%) } & \multicolumn{2}{|c|}{$\begin{array}{l}\text { Uncertainty } \\
\text { analysis }\end{array}$} \\
\hline & & & & $\overline{N S E}$ & $R^{2}$ & & p-factor & r-factor \\
\hline \multirow[t]{8}{*}{ Daily } & \multirow[t]{3}{*}{ SSC } & Logone Gana (outlet) & $2000-2007$ & 0.64 & 0.65 & 6.10 & 0.42 & 0.50 \\
\hline & & Katoa (middle ridge) & $2000-2007$ & 0.72 & 0.75 & -15.12 & 0.65 & 0.92 \\
\hline & & Bongor (upstream) & 2000-2007 & 0.66 & 0.68 & 11.60 & 0.64 & 0.65 \\
\hline & \multirow[t]{2}{*}{$\mathrm{SC}$} & Bongor (upstream) & $2000-2007$ & 0.71 & 0.74 & 3.50 & 0.76 & 0.89 \\
\hline & & Katoa (middle ridge) & $2000-2007$ & 0.75 & 0.79 & 13.70 & 0.84 & 1.01 \\
\hline & \multirow[t]{3}{*}{ SMSC } & Logone Gana (outlet) & 2000-2007 & 0.53 & 0.66 & -3.10 & 0.79 & 0.90 \\
\hline & & Katoa (middle ridge) & $2000-2007$ & 0.75 & 0.77 & 16.10 & 0.71 & 0.69 \\
\hline & & Bongor (upstream) & $2000-2007$ & 0.56 & 0.69 & 35.10 & 0.61 & 0.49 \\
\hline \multirow[t]{12}{*}{ Monthly } & \multirow[t]{4}{*}{$\mathrm{SSC}$} & Logone Gana (outlet) & $2000-2007$ & 0.68 & 0.88 & 10.30 & 0.85 & 0.88 \\
\hline & & & 2008-2010 & 0.66 & 0.72 & 5.20 & 0.50 & 0.56 \\
\hline & & Katoa (middle ridge) & $2000-2007$ & 0.78 & 0.83 & -12.40 & 0.88 & 1.12 \\
\hline & & Bongor (upstream) & 2000-2010 & 0.72 & 0.76 & 21.00 & 0.75 & 0.74 \\
\hline & \multirow[t]{3}{*}{$\mathrm{SC}$} & Bongor (upstream) & $2000-2007$ & 0.76 & 0.79 & -5.12 & 0.85 & 0.93 \\
\hline & & & 2008-2010 & 0.76 & 0.86 & -22.90 & 0.81 & 0.91 \\
\hline & & Katoa (middle ridge) & $2000-2007$ & 0.81 & 0.81 & 9.80 & 0.85 & 1.05 \\
\hline & \multirow[t]{5}{*}{ SMSC } & Logone Gana (outlet) & $2000-2007$ & 0.64 & 0.68 & -4.70 & 0.82 & 1.06 \\
\hline & & & 2008-2010 & 0.44 & 0.57 & -33.20 & 0.47 & 0.67 \\
\hline & & Katoa (middle ridge) & $2000-2007$ & 0.80 & 0.81 & 10.00 & 0.84 & 0.94 \\
\hline & & Bongor (upstream) & 2000-2007 & 0.61 & 0.73 & 31.10 & 0.71 & 0.69 \\
\hline & & & $2008-2010$ & 0.69 & 0.72 & -16.10 & 0.61 & 0.52 \\
\hline
\end{tabular}

Calibration period (2000-2007) while the validation period (2008-2010). Note that for single site calibration, the model was also validated using data from upstream gauging stations (Kato and Lai)

Gana as explained in Sect. 3.1.4 below. This could also suggest that by using SSC technique it may not possible to adequately represent all the hydrological processes taking place in the catchment. Therefore, the optimized model parameters may not be considered to be representative of the catchment and justifies the need for different calibration techniques.

\subsubsection{Model performance for sequential calibration}

This technique was used to calibrate the model at two internal stations located upstream of the catchment outlet so as to take into account the variability in the spatial characteristics of the sub-basins that contribute to streamflow. Model evaluation statistics at both time-steps show that the NSE and $R^{2}$ values obtained lie in the range $0.71 \leq N S E \leq 0.81$ and $0.74 \leq R^{2} \leq 0.86$, which are all above the threshold defined in this study (Table 3). Results for peak flow simulation using SC at Katoa and Bongor are mixed with cases of flow overestimation/underestimation in some years while baseflow is adequately simulated (Fig. 5a, b). The results for peak flow simulation at monthly time-step are comparable to what was obtained at daily time-step but baseflow is slightly overestimated in some years during validation at Bongor station (Fig. 6b, c). Using this technique, the water balance predicted by the model at both time-steps during calibration and validation all lie within the threshold defined by in this study (Table 3).

From NSE and $R^{2}$ values obtained, it can be observed that this technique out-performed the SSC (Table 3). For example, by changing the calibration technique from SSC to $\mathrm{SC}$, the NSE value for Bongor increased from 0.66 to 0.71 while PBIAS at the same station dropped from 11.60 to $3.50 \%$ at the daily time-step. This shows a significant improvement in the model performance. This suggest that by using the SC technique, the model parameter values representing the spatial variability and processes taken place at sub-basins located upstream of the calibrated gauging station are adequately represented.

\subsubsection{Simultaneous multi-site calibration}

In the SMSC approach, all the gauging stations were calibrated at the same time. Results obtained show that, at both time-steps, NSE and $R^{2}$ values lie in the range 
Fig. 4 Comparison daily observed and simulated hydrographs for SSC (a) and validation of SSC at upstream gauging stations $(\mathbf{b}, \mathbf{c})$
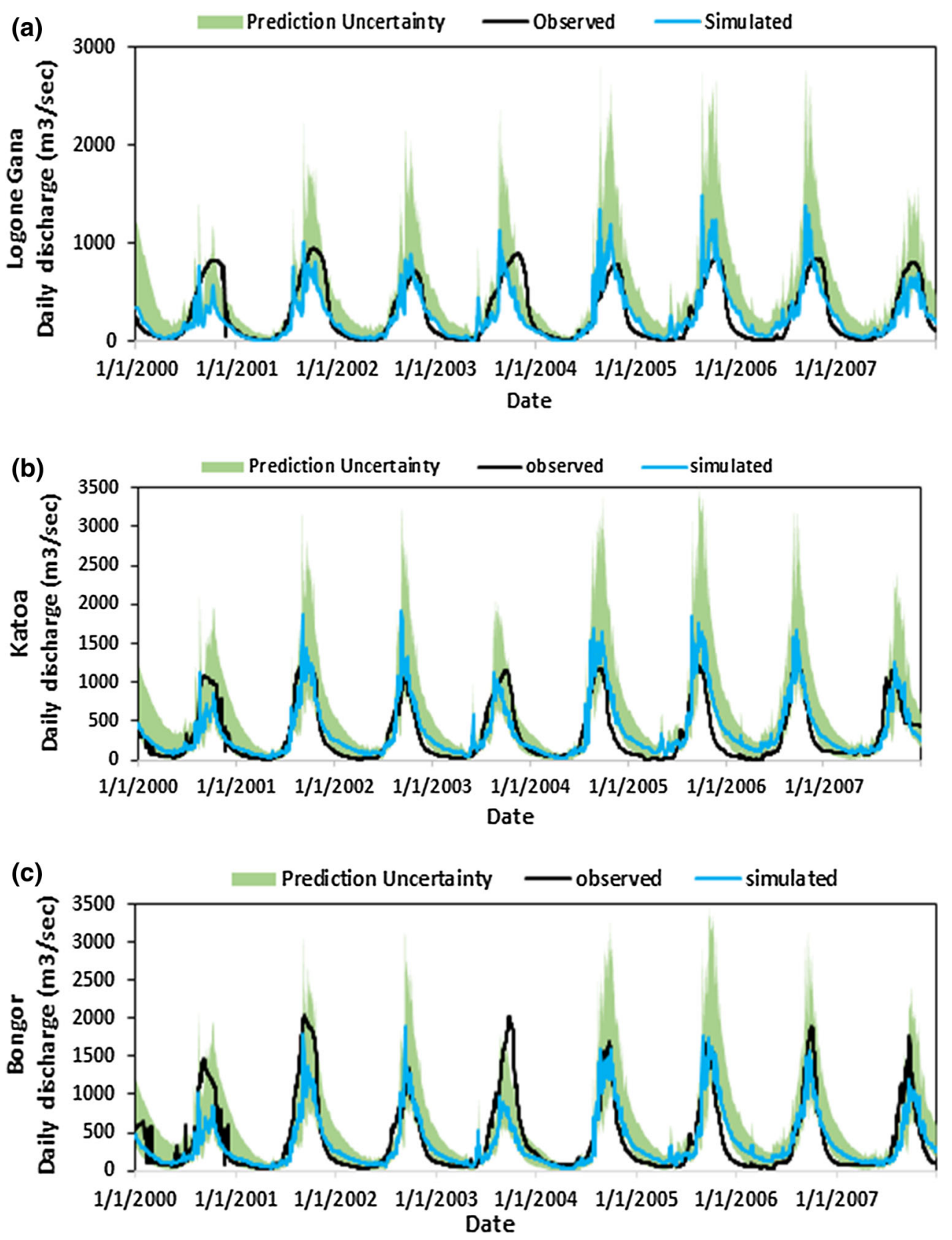

$0.44 \leq N S E \leq 0.80$ and $0.57 \leq R^{2} \leq 0.81$ (Table 3). It can be observed that by using this technique, the model performed better during calibration at monthly time-step at all the gauging stations compared to the daily time-step (Figs. 6a-c, 7a-c). At the monthly time-step the model performance slightly improved during validation at Bongor whereas it deteriorated at Logone Gana (Table 3). At the outlet, the model systematically overestimated peak flows during calibration at both time-steps and during validation at monthly time-step with the exception of 2009 during the validation period when the model underestimated peak flows (Figs. 5a, 6a). On the other hand, the model underestimated peak flows at Katao in some years during calibration at both time-steps (Figs. 6b, 7b). Meanwhile at Bongor, the model systematically underestimated peak flow in all the years at the daily and monthly time-steps (Figs. 6c, 7c).

The PBIAS values obtained during calibration lie within the threshold defined in this study except for Logone Gana during validation at monthly time-step and Bongor during calibration at both time-steps. 
Fig. 5 Comparison daily observed and simulated hydrographs for sequential calibration $(\mathbf{a}, \mathbf{b})$
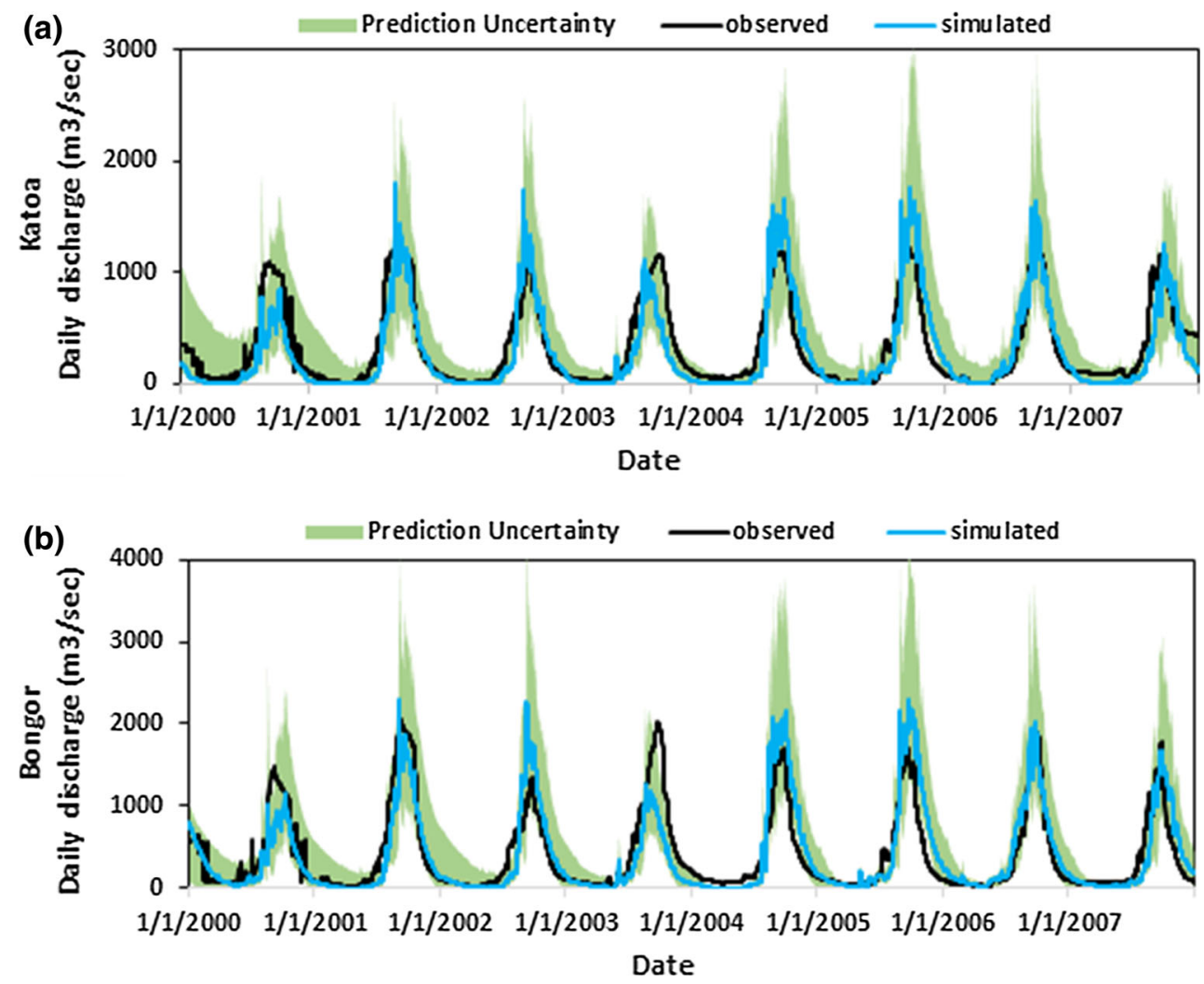

\subsubsection{Comparison of different calibration methods}

Comparing the results obtained using the three calibration techniques, SC produced the best performance considering all the three model performance metrics, followed by SSC while SMSC produced average performance although still above the minimum criteria defined in this study (Table 3 ). These results follow the findings of Leta et al. (2017) who observed that SC out-performed the SSC technique in their study. Comparing the streamflow hydrographs obtained using the three techniques, it can be observed that; (1) with the SSC technique peak flows were overestimated at the outlet and at Katoa during validation upstream (Figs. 4a, b, $7 \mathrm{a}, \mathrm{b})$. Validating this technique using data from Bongor further upstream led to the underestimation of peak flows in most years (Figs. 4c, 7c), (2) SC technique lead to the overestimation of peak flows in some years at Bongor during the calibration and validation periods (Fig. 7c), and (3) SMSC technique led to the overestimation of peak flows at the outlet and underestimation of peak flows at the upstream stations (Fig. 7a-c). However, using this technique, baseflow was systematically overestimated during validation at Logone Gana and Bongor (Fig. 7a, c). Model under-performance during the validation period can be attributed to the fact that there was no warm-up period during validation so the model could not acclimatize. Generally, using all the techniques, baseflow was well simulated across all stations except at Logone Gana and Bongor using the SSC and SMSC techniques during the validation period (2008-2010).

Applying all the three calibration techniques, it was observed that the model performance increased from upstream (Bongor) to downstream (Katoa). However, moving further downstream at the outlet, there was a drop in model performance. This drop can be explained by the fact that between Katoa and Logone Gana (outlet), there is a dam on the left bank of the Logone River. There are also discharge elements (weirs, spillway) located on the left bank of the river downstream of Katoa, which provide a hydraulic connection between the river and the dam. These structures can send water either way depending on the water level in the river channel and the dam and contribute to modifying the hydraulic/hydrologic behavior of the river/catchment. The approach adopted in this study was for the dam to release water whenever its storage capacity was exceeded. Thus the drop in model performance at the outlet can be attributed to this complexity, which was not implemented in the model.

Despite the marginal performance of SMSC at some stations compared to $\mathrm{SC}$, this technique may be preferable to $\mathrm{SC}$ because it can represent the spatial variability in the catchment using lump parameters and all gauging stations are calibrated at the same time. Therefore, for basin wide application of model results, it may be preferable to use the 
Fig. 6 Comparison daily observed and simulated hydrographs for SMSC (a-c)
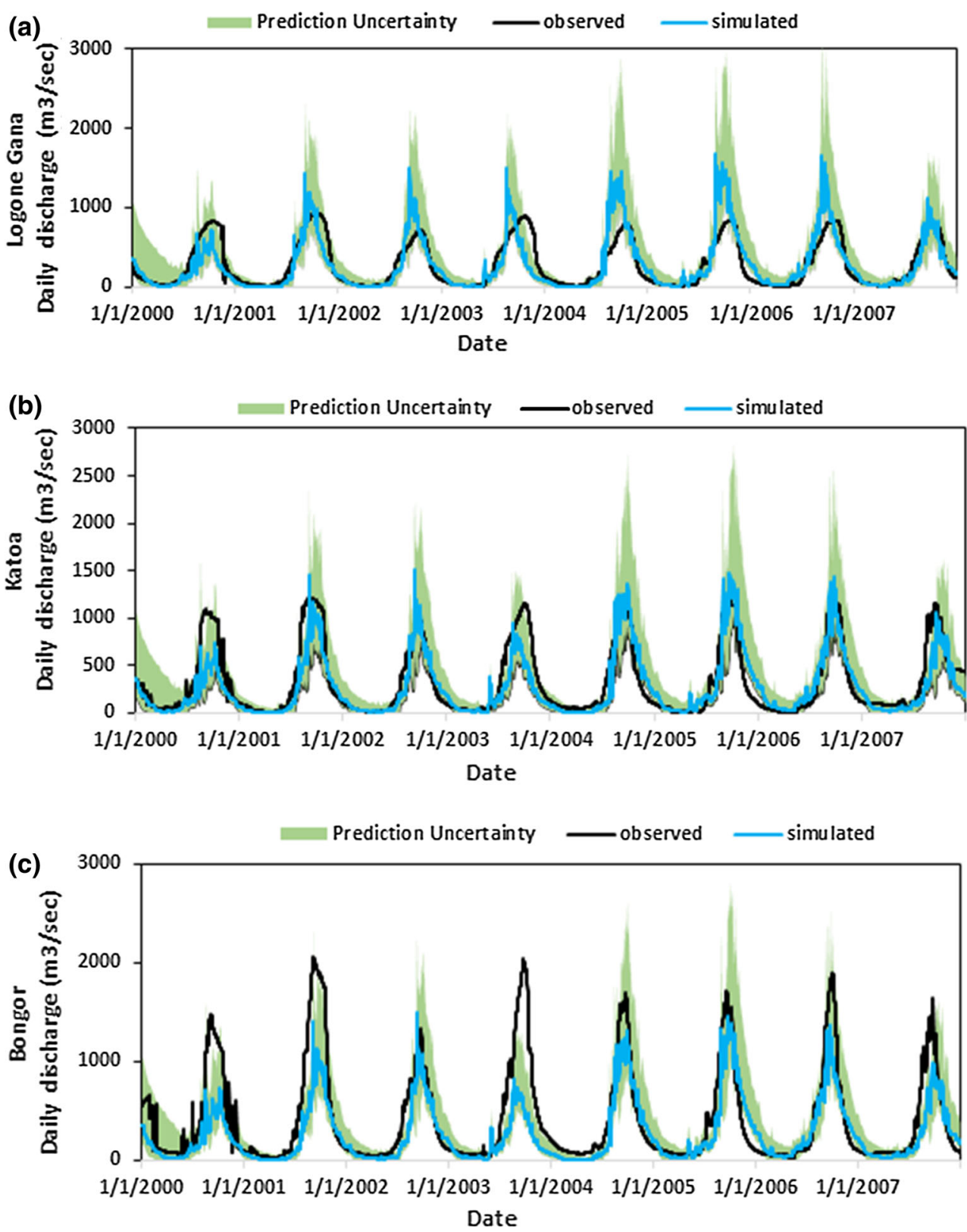

SMSC technique. More so, because of the hydrologic connectivity between the gauging stations so there is information exchange between the stations during calibration. In addition, using the SMSC technique it is possible to calibrate the model at all spatial levels (basin, sub-basin and HRU). Despite these advantages offered by SMSC, the use of each calibration technique should be guided by the type of management decision and the spatial scale of implementation in the catchment.

\subsection{Model prediction uncertainty}

The model predictive uncertainty was evaluated using the $p$-factor and r-factor with the objective to minimize the width of the uncertainty band and enclose as many observations as possible. Results of SSC model predictive uncertainty indicated that low $r$-factor values $(<1.50)$ and high $p$-factor values $(>0.70)$ were obtained during model calibration at the monthly time-step compared to daily time-step (Table 3). However, this was not the case during model validation at the monthly time-step because only $50 \%$ of observed flows were bracketed within the 95PPU band. This under-performance during validation can be attributed to the short period used for validation so there was no warm-up period. It was also observed that more than $60 \%$ of observed daily streamflow was bracketed within 95PPU during validation and the r-factor values obtained at the two sites used for validation were $<1.50$ 
Fig. 7 Comparison of monthly observed and simulated hydrographs using the different calibration techniques. The uncertainty band is not included because the hydrographs have been obtained using different calibration techniques. Notice that at Katoa, SC and SMSC produced almost identical hydrographs
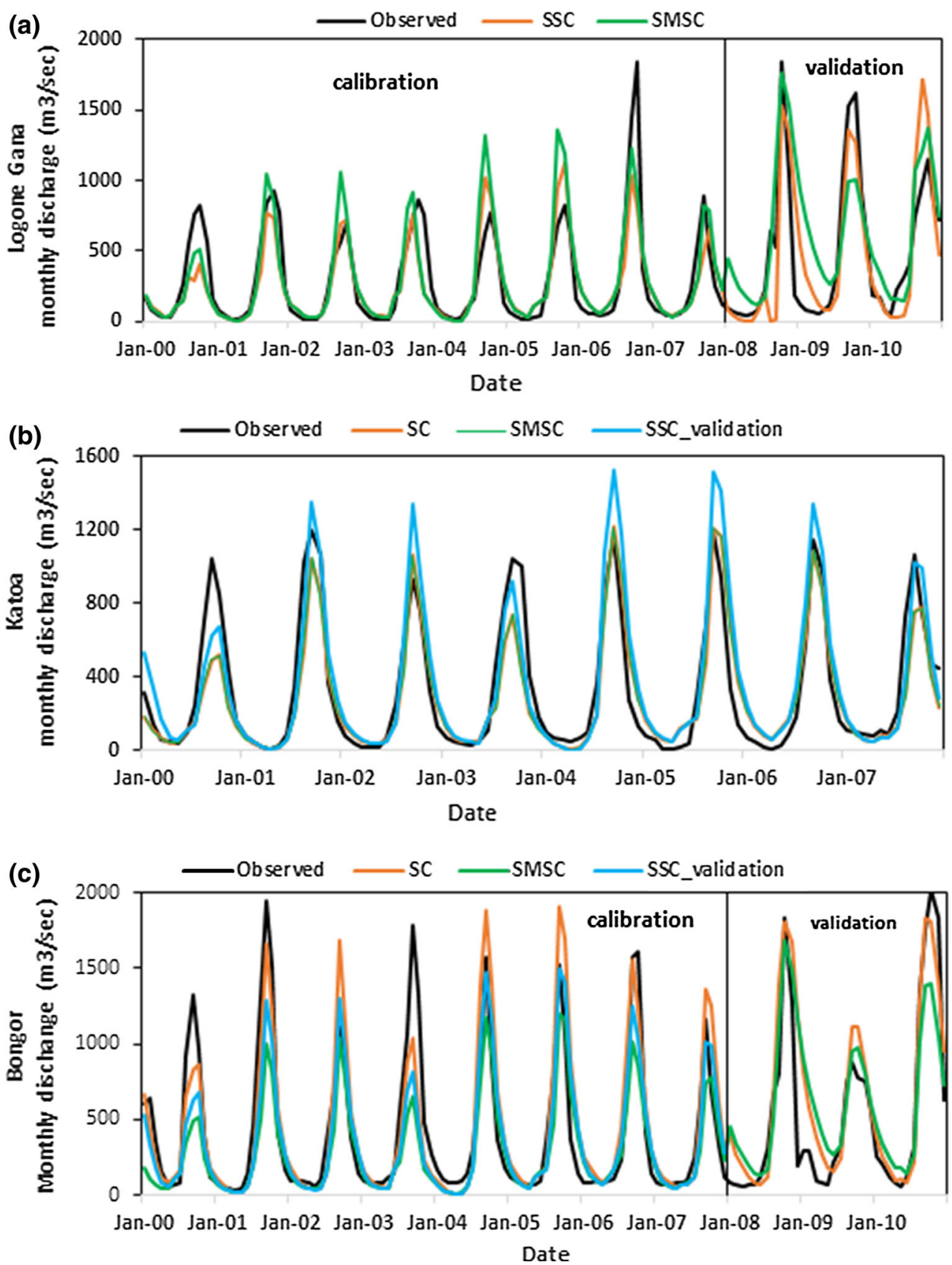

(Fig. 3a-c). Uncertainty analysis using the SC technique showed that more than $75 \%$ of observed streamflow was bracketed within the 95PPU band with very low $r$-factor values $<1.50$ recorded at both time-steps but the model performed better at monthly time-step compared to daily (Table 3). Using the SMSC technique, uncertainty analysis results indicated that across all the stations, $>60 \%$ of daily observed streamflow was bracketed within the 95PPU with $r$-factor values obtained generally $<1.50$. Apart from model validation at Logone Gana, similar model prediction uncertainty values were recorded at a monthly time-step (Table 3).
Generally, it was observed that the SC technique outperformed the other two methods (SSC and SMSC) in terms of model prediction uncertainty. Meanwhile, Katoa station registered the best performance at both daily and monthly time-steps. This is because the percentage of observed flow bracketed within the 95PPU band was generally above $65 \%$ irrespective of the technique used. The improved performance of the model predictive uncertainty and other evaluation indices at monthly time-step compared to daily can be attributed to the fact that, monthly rainfall is a cumulative measurement in which, all the daily variability within the month is summed thus reducing the 
variability and uncertainty in the data. This reduced variability consequently led to an improvement in the model performance.

Despite the positive results obtained, model bias (uncertainty band) was slightly wider at some stations (Figs. 4, 5, 6). This could be attributed to the uncertainty inherent in the rainfall estimates (WFDEI) used in driving the model and reinforces the importance of using accurate rainfall estimates in hydrological modelling. In fact, Weiland et al. (2015) have shown that the uncertainty in rainfall estimates used in driving a hydrological model is propagated through the model to the streamflow estimates. This bias could also be linked to the uncertainty in the observed streamflow data used to calibrate the model. The uncertainty in streamflow could arise from the inability to accurately measure high flows at the river gauging stations or from rating equations when converting gauge heights of high flows to discharge (Juston et al. 2014). What could not be ruled out here was the possibility of observations errors in discharge resulting from poor or irregular maintenance of the gauge stations and/or the measurement equipment. Other sources of uncertainty e.g. model structural uncertainty and parameter uncertainty were deemed out of scope of this study and therefore are not discussed herein.

\subsection{Parameter estimation}

Given that we had no prior knowledge of the dominant hydrological processes that take place in the catchment, in this study feasible ranges of the calibrated parameters obtained from the literature were used (as is often the case in most automatic hydrologic model calibration).

Comparing the values of the optimized parameters using the different techniques, it was observed that there were significant differences in the parameter values obtained using each of the techniques. Using the SSC and SMSC techniques indicated that streamflow was consistently high therefore, $\mathrm{CN} 2$ was reduced by factor of -0.35 across the catchment. However, it can be observed from the flow hydrographs that reducing $\mathrm{CN} 2$ led to the underestimation of peak flow at Bongor (Figs. 4c, 6c, 7c). On the contrary, by applying the SC technique at Bongor, CN2 increased by 0.05 and peak flows were instead slightly overestimated in some years at this station (Figs. 5b, 7c). This suggest that, the response of the upstream and downstream parts of the catchment to are different.

In fact, $65 \%$ of the total catchment area upstream of Bongor station is located in the Sudano zone which is mostly covered by forest and receives the highest amount of rainfall. While the remaining part of the catchment from Bongor to Logone Gana is located in the semi-arid zone with low rainfall and very flat topography with numerous wetlands (Fig. 1b). Thus the differences in response to streamflow in the two parts of the catchment could be partly attributed to their physical characteristics. This suggest that $\mathrm{CN} 2$ values could be slightly higher in the upstream part (Sudano zone) of the catchment compared to downstream (semi-arid zone).

During the calibration process, SMSC uses streamflow data from different parts of the catchment. In this study, streamflow data from two stations located in the semi-arid part of the catchment (Katoa and Logone Gana) was used for calibration while data from only one station in the Sudano area was used. Therefore, the calibration process may have been dominated by semi-arid characteristics while the characteristics of the Sudano area that had data from only one gauging station were obscured. This could partly explain why by applying the SMSC technique, streamflow was systematically underestimated at Bongor due to a reduction in $\mathrm{CN} 2$ in the upstream part of the catchment. By using the $\mathrm{SC}$ technique, it is possible to unmask the differences in catchment characteristics that may not be revealed by SSC and SMSC. This is because these techniques use lump parameter values which may not represent the physical characteristics of the catchment.

The average values of GW_delay and Alpha_BF obtained using the SC at Bongor indicate that the Sudano area of the catchment has moderate response to groundwater recharge (Table 1). This follows the findings of Candela et al. (2014) who reported that in the southern part of the LCB covering the Logone catchment, high rainfall, the gentle topography and the kinds of soils found there favour aquifer recharge through rainfall infiltration. In contrast, the high GW_delay and low Alpha_BF values obtained by applying the SSC and SMSC techniques at the outlet and the SC technique at Katoa indicate that infiltration and groundwater recharge are low in this part of the catchment. These results are in agreement with the findings of Westra and De Wulf (2009) who attributed flooding in Logone wetlands to high soil water content during rainy season as a result of low infiltration capacity of the soils.

\subsection{Evaluation of water balance}

Given the ability of the SMSC technique to take into account the spatial variability in catchment processes, the water balance in the catchment was evaluated using output derived by this technique. Results of average annual water balance components during calibration indicate that, $73 \%$ of total precipitation in the catchment was lost through evapotranspiration, $7.68 \%$ contributed to re-evaporation, $12.83 \%$ contributed to groundwater (shallow and deep groundwater flow) while $<8 \%$ contributed to lateral flow and surface runoff (Table 4). Similar evapotranspiration and groundwater flow estimates were obtained in the Ouemé river basin using SWAT e.g. (Ollivier et al. 2014). 
The surface runoff values produced by SWAT in this study are comparable to those obtained by $\mathrm{Li}$ et al. (2005) at Ndjamena gauging station located downstream of Logone Gana. Analysis further showed that, more than $50 \%$ of the total catchment water yield was contributed by groundwater flow. Water yield is comprised of surface water, (Surf Q), lateral flow (Lat Q) and base flow contribution to discharge (GW Q) minus transmission losses through the channel bed, which contribute to groundwater recharge.

\subsection{Impact of wetlands flow regime}

Our analysis showed that within the study domain, the model was not sensitive to the impacts of wetlands on flow hydrographs using the different wetland modelling options available in SWAT (Neitsch et al. 2011). When this was observed, the normal storage volume was changed to maximum storage as suggested by Wang et al. (2010) by increasing the value of $f r_{i m p}$ from 0.50 to 1.0 the hydrograph did not change after simulation. The water level in the wetland was changed from 0.50 to 1.0 and multiplied by wetland area $(S A)$ yet no change was observed. The maximum storage volume was multiplied by 2 as suggested by Almendinger et al. (2014) and there was no change in the hydrographs after simulation. All changes to implement the wetland options were effectuated in project database before running the model to see the changes. Note that it was not possible to model the impact of wetlands at individual sub-basin level because this required discharge data at the outlet of each sub-basin, which practically is not possible.

We therefore, attribute this minimal change in flow hydrographs to the relatively small surface area occupied by wetlands (2\%) compared to the total surface area of the study domain $\left(86,240 \mathrm{~km}^{2}\right)$. In previous studies, Cohen Liechti et al. (2014) and Feng et al. (2013) questioned the capability of SWAT model to simulate water fluxes from wetlands. In another study using SWAT, Martinez-Martinez et al. (2014) reported that wetland restoration did not have any significant impact on peak flows. The minimal impact of wetlands on the flow regime of the Logone as observed in this study may also be attributed to the location of the wetlands with respect to the main river channel (most wetlands are located on tributary channels) and also because many of the wetlands especially in the upstream part of the catchment had surface areas $<50$ ha. This follows the findings of Martinez-Martinez et al. (2014) who asserted that wetlands with surface area measuring $<50$ ha or those located on tributary channels had negligible impact on streamflow hydrograph(s) of the main channel.

\section{Conclusion}

The objectives of this study were to develop, calibrate, and validate a hydrological model of the Logone catchment using the SWAT model, test the benefits of the different calibration techniques (Single-Site Calibration, Sequential Calibration and Simultaneous Multi-site Calibration) and attempt a description of the catchment hydrology.

By using the different calibration techniques, it was possible to show using different parameter values, the differences in hydrological behavior between the upstream and downstream parts of the catchment, which was not possible using only one calibration technique. This demonstrates that by using different calibration techniques, it is possible to unmask the differences in catchment characteristics that cannot be revealed by one technique especially in heterogeneous catchments.

Results also showed that using many streamflow gauges from only one spatial zone within the catchment at the expense of the other zone(s) during the SMSC may lead to parameter values from the zone with many gauges dominating the parameter space. This may obscure the spatial
Table 4 Results of simulated average water balance components $(\mathrm{mm})$

\begin{tabular}{|c|c|c|}
\hline \multirow[t]{2}{*}{ Hydrologic water components } & \multicolumn{2}{|l|}{ Model with SWAT } \\
\hline & Calibration (2000-2007) & Validation (2008-2010) \\
\hline Precipitation & 1229.20 & 1163.80 \\
\hline Surface runoff & 8.87 & 6.09 \\
\hline Lateral flow & 14.61 & 15.26 \\
\hline Shallow groundwater flow & 157.65 & 152.36 \\
\hline Groundwater re-evaporation & 94.49 & 84.31 \\
\hline Total water yield & 210.47 & 308.02 \\
\hline Percolation out of the soil & 307.27 & 296.88 \\
\hline Evapotranspiration & 900.10 & 844.00 \\
\hline Potential Evapotranspiration ${ }^{\mathrm{a}}$ & 1958.60 & 1966.20 \\
\hline
\end{tabular}

${ }^{a}$ Potential evapotranspiration is not part of the water balance 
variability, which is the most important catchment attribute that this technique is supposed to reveal. This reinforces the importance of installing many hydrometric stations along the river network.

Results from this study showed that the SC technique out-performed the other two methods (SSC and SMSC). Although the SMSC takes into account the spatial variability in the catchment, information exchange between the stations during calibration, and reduced simulation time, it may be preferable to the other methods albeit marginal performance. However, the choice of each calibration method will depend on the scale of application of the modelling results.

Evaluation of catchment water balance using SMSC indicated that evapotranspiration was the dominant hydrological process through which about $73 \%$ of total precipitation received in the catchment is lost. Furthermore, more than $50 \%$ of the total water yield is contributed by groundwater flow suggesting that, groundwater plays a significant role in the catchment hydrology. Results also indicated that within the catchment domain studied wetlands did not play a significant role in the hydrological regime of the Logone River.

Given the complexity of the study area and the fact that this is the first large-scale hydrological modelling attempt in the catchment, the results obtained in this study can be considered to be satisfactory given that more than $60 \%$ of daily observed streamflow values were captured within the 95PPU band. Analysis of the catchment hydrology carried out in the present study may be invaluable to enhance water resources management to increase agricultural production, investigate the impact of land use change, simulate rainfallrunoff prediction and conduct climate change impact assessment. It is hoped that future modelling studies in the catchment will build from results obtained in the present study. Results from this study also show that WFDEI could be used for hydrological modelling in data-scarce regions like the Sudano-Sahel.

Acknowledgements This research was supported through a Commonwealth Scholarship award to the first author. The authors are indebted to Lund University, IIASA, LCBC, Jet Propulsion Laboratory, ESA and FAO for providing the data used in this study.

Open Access This article is distributed under the terms of the Creative Commons Attribution 4.0 International License (http://crea tivecommons.org/licenses/by/4.0/), which permits unrestricted use, distribution, and reproduction in any medium, provided you give appropriate credit to the original author(s) and the source, provide a link to the Creative Commons license, and indicate if changes were made.

\section{References}

Abbaspour K (2008) SWAT-CUP2: SWAT calibration and uncertainty programs-a user manual. Department of systems analysis. Integrated assessment and modelling (SIAM), Eawag, Swiss Federal Institute of Aquatic Science and Technology, Duebendorf, Switzerland

Adenle D (2001) Groundwater resources and environmental management in Niger Basin Authority and Lake Chad Basin Commission agreements. UIPO, Ibadan

Aich V, Liersch S, Vetter T, Andersson J, Müller EN, Hattermann FF (2015) Climate or land use? Attribution of changes in river flooding in the Sahel Zone. Water 7:2796-2820

Akpoti K, Antwi EO, Kabo-Bah AT (2016) Impacts of rainfall variability, land use and land cover change on stream flow of the black Volta Basin, West Africa. Hydrology 3:26

Almendinger JE, Murphy MS, Ulrich JS (2014) Use of the Soil and Water Assessment Tool to scale sediment delivery from field to watershed in an agricultural landscape with topographic depressions. J Environ Qual 43:9-17

Andersson J, Pechlivanidis I, Gustafsson D, Donnelly C, Arheimer B (2015) Key factors for improving large-scale hydrological model performance. Eur Water 49:77-88

Arnold JG, Moriasi DN, Gassman PW, Abbaspour KC, White MJ, Srinivasan R, Santhi C, Harmel R, Van Griensven A, Van Liew MW (2012) SWAT: model use, calibration, and validation. Trans ASABE 55:1491-1508

Athira P, Sudheer KP (2015) A method to reduce the computational requirement while assessing uncertainty of complex hydrological models. Stoch Env Res Risk Assess 29:847-859

Candela L, Elorza F, Tamoh K, Jiménez-Martínez J, Aureli A (2014) Groundwater modelling with limited data sets: the Chari-Logone area (Lake Chad Basin, Chad). Hydrol Process 28:3714-3727

Chaibou Begou J, Jomaa S, Benabdallah S, Bazie P, Afouda A, Rode M (2016) Multi-site validation of the SWAT model on the bani catchment: model performance and predictive uncertainty. Water 8:178

Cohen Liechti T, Matos JP, Ferràs Segura D, Boillat J-L, Schleiss AJ (2014) Hydrological modelling of the Zambezi River Basin taking into account floodplain behaviour by a modified reservoir approach. Int J River Basin Manag 12:29-41

Droogers P, Allen RG (2002) Estimating reference evapotranspiration under inaccurate data conditions. Irriga Drain Syst 16:33-45

Feng X, Zhang G, Xu YJ (2013) Simulation of hydrological processes in the Zhalong wetland within a river basin, Northeast China. Hydrol Earth Syst Sci 17:2797

Gassman PW, Reyes MR, Green CH, Arnold JG (2007) The soil and water assessment tool: historical development, applications, and future research directions. Trans ASABE 50:1211-1250

Golmohammadi G, Prasher S, Madani A, Rudra R (2014) Evaluating three hydrological distributed watershed models: MIKE-SHE, APEX, SWAT. Hydrology 1:20

Jung HC, Alsdorf D, Moritz M, Lee H, Vassolo S (2011) Analysis of the relationship between flooding area and water height in the Logone floodplain. Phys Chem Earth Parts A/B/C 36:232-240

Juston J, Jansson PE, Gustafsson D (2014) Rating curve uncertainty and change detection in discharge time series: case study with 44-year historic data from the Nyangores River, Kenya. Hydrol Process 28:2509-2523

Leta OT, Van Griensven A, Bauwens W (2017) Effect of single and multisite calibration techniques on the parameter estimation, performance, and output of a SWAT model of a spatially heterogeneous catchment. J Hydrol Eng 22:05016036 
Li K, Coe M, Ramankutty N (2005) Investigation of hydrological variability in West Africa using land surface models. J Clim 18:3173-3188

Lin S, Jing C, Coles NA, Chaplot V, Moore NJ, Wu J (2013) Evaluating DEM source and resolution uncertainties in the Soil and Water Assessment Tool. Stoch Environ Res Risk Assess 27:209-221

Martinez-Martinez E, Nejadhashemi AP, Woznicki SA, Love BJ (2014) Modeling the hydrological significance of wetland restoration scenarios. J Environ Manag 133:121-134

Migliaccio KW, Chaubey I (2007) Comment on Cao W, Bowden BW, Davie T, Fenemor A. 2006. Multi-variable and multi-site calibration and validation of SWAT in a large mountainous catchment with high spatial variability'. Hydrological Processes 20(5): 1057-1073. Hydrol Process 21:3226-3228

Monteiro JA, Strauch M, Srinivasan R, Abbaspour K, Gücker B (2015) Accuracy of grid precipitation data for Brazil: application in river discharge modelling of the Tocantins catchment. Hydrol Process 30:1419-1430

Moriasi DN, Arnold JG, Van Liew MW, Bingner RL, Harmel RD, Veith TL (2007) Model evaluation guidelines for systematic quantification of accuracy in watershed simulations. Trans ASABE 50:885-900

Neitsch SL, Arnold JG, Kiniry JR, Williams JR (2011) Soil and water assessment tool theoretical documentation version 2009. Texas Water Resources Institute, College Station

Ngatcha BN (2009) Water resources protection in the Lake Chad Basin in the changing environment. Eur Water 25:3-12

Nkiaka E, Nawaz N, Lovett J (2016a) Analysis of rainfall variability in the Logone catchment, Lake Chad basin. Int J Climatol 37:3553-3564

Nkiaka E, Nawaz NR, Lovett JC (2016b) Using self-organizing maps to infill missing data in hydro-meteorological time series from the Logone catchment, Lake Chad basin. Environ Monit Assess 188:1-12

Nkiaka E, Nawaz N, Lovett JC (2017) Evaluating global reanalysis datasets as input for hydrological modelling in the Sudano-Sahel region. Hydrology 4:13

Odada EO, Oyebande L, Oguntola AJ (2005) Lake Chad: experience and lessons learned brief. http://www.worldlakes.org/uploads/ 06_lake_chad_27february2006.pdf. Accessed 19 Oct 2017

Okpara UT, Stringer LC, Dougill AJ, Bila MD (2015) Conflicts about water in Lake Chad: are environmental, vulnerability and security issues linked? Prog Dev Stud 15:308-325

Ollivier SL, Barnabé Z, Maurice AD, Expédit VW, Euloge AK (2014) Modelling the water balance of ouémé catchment at the savè outlet in Benin: contribution to the sustainable water resource management. Int J AgriSci 4:74-88

Onyutha C (2016) Influence of hydrological model selection on simulation of moderate and extreme flow events: a case study of the Blue Nile basin. Adv Meteorol 2016:28
Shi H, Li T, Wang K, Zhang A, Wang G, Fu X (2016) Physically based simulation of the streamflow decrease caused by sedimenttrapping dams in the middle Yellow River. Hydrol Process 30:783-794

Shrestha MK, Recknagel F, Frizenschaf J, Meyer W (2016) Assessing SWAT models based on single and multi-site calibration for the simulation of flow and nutrient loads in the semi-arid Onkaparinga catchment in South Australia. Agric Water Manag 175:61-71

Wang X, Shang S, Qu Z, Liu T, Melesse AM, Yang W (2010) Simulated wetland conservation-restoration effects on water quantity and quality at watershed scale. J Environ Manag 91:1511-1525

Wang S, Zhang Z, Sun G, Strauss P, Guo J, Tang Y, Yao A (2012) Multi-site calibration, validation, and sensitivity analysis of the MIKE SHE Model for a large watershed in northern China. Hydrol Earth Syst Sci 16:4621-4632

Weedon GP, Balsamo G, Bellouin N, Gomes S, Best MJ, Viterbo P (2014) The WFDEI meteorological forcing data set: WATCH forcing data methodology applied to ERA-interim reanalysis data. Water Resour Res 50:7505-7514

Weiland FCS, Vrugt JA, Weerts AH, Bierkens MF (2015) Significant uncertainty in global scale hydrological modeling from precipitation data errors. J Hydrol 529:1095-1115

Westra T, De Wulf R (2009) Modelling yearly flooding extent of the Waza-Logone floodplain in northern Cameroon based on MODIS and rainfall data. Int J Remote Sens 30:5527-5548

Wi S, Yang YCE, Steinschneider S, Khalil A, Brown CM (2015) Calibration approaches for distributed hydrologic models in poorly gaged basins: implication for streamflow projections under climate change. Hydrol Earth Syst Sci 19:857-876

Wu Y, Chen J (2013) Analyzing the water budget and hydrological characteristics and responses to land use in a monsoonal climate river basin in South China. Environ Manag 51:1174-1186

Wu S, Li J, Huang G (2008) Characterization and evaluation of elevation data uncertainty in water resources modeling with GIS. Water Resour Manag 22:959

Yang Y, Guan H, Batelaan O, Mcvicar TR, Long D, Piao S, Liang W, Liu B, Jin Z, Simmons CT (2016) Contrasting responses of water use efficiency to drought across global terrestrial ecosystems. Sci Rep 6:23284

Zhang A, Li T, Si Y, Liu R, Shi H, Li X, Li J, Wu X (2016) Doublelayer parallelization for hydrological model calibration on HPC systems. J Hydrol 535:737-747

Zhou J, He D, Xie Y, Liu Y, Yang Y, Sheng H, Guo H, Zhao L, Zou R (2015) Integrated SWAT model and statistical downscaling for estimating streamflow response to climate change in the Lake Dianchi watershed, China. Stoch Environ Res Risk Assess 29:1193-1210 